\title{
High contribution and impact of resistant gram negative pathogens causing surgical site infections at a multi-hospital healthcare system in Saudi Arabia, 2007-2016
}

Aiman El-Saed ${ }^{1,2,3}$, Hanan H. Balkhy ${ }^{1,2,4^{*}}$, Majid M. Alshamrani ${ }^{1,2}$, Sameera Aljohani ${ }^{5}$, Asim Alsaedi ${ }^{6}$, Wafa Al Nasser ${ }^{7}$, Ayman El Gammal ${ }^{8}$, Saad A. Almohrij ${ }^{9}$, Ziyad Alyousef ${ }^{9}$, Sara Almunif ${ }^{1}$ and Mohammad Alzahrani ${ }^{10}$

\begin{abstract}
Background: Despite being largely preventable, surgical site infections (SSIs) are still one of the most frequent healthcare-associated infections. The presence of resistant pathogens can further augment their clinical and economic impacts. The objective was to estimate the distribution and resistance in SSI pathogens in Saudi Arabia and to compare them to the US National Healthcare Safety Network (NHSN) hospitals.

Methods: Targeted SSI surveillance was prospectively conducted on several surgical procedures done between 2007 and 2016 in four hospitals of Ministry of National Guard Health Affairs. Definitions and methodology of SSI and bacterial resistance were based on NHSN.

Results: A total 492 pathogens causing 403 SSI events were included. The most frequent pathogens were Staphylococcus aureus (22.8\%), Pseudomonas aeruginosa (20.1\%), Klebsiella spp. (12.2\%), and Escherichia coli (12.2\%), with marked variability between surgeries. Approximately 30.3\% of Staphylococcus aureus was methicillin-resistant (MRSA), 13.0\% of Enterococcus spp. was vancomycin-resistant (VRE), and 5.5\% of Enterobacteriaceae were carbapenem resistant (CRE). The highest multidrug-resistant (MDR) GNPs were Acinetobacter spp. (58.3\%), Klebsiella spp. (20.4\%) and Escherichia coli (16.3\%). MRSA was significantly less frequent while cephalosporin-resistant Klebsiella spp., MDR Klebsiella spp., and MDR Escherichia coli were significantly more frequent in our hospitals compared with NHSN hospitals.

Conclusion: GNPs in a tertiary care setting in Saudi Arabia are responsible for more than $60 \%$ of SSI with more resistant patterns than Western countries. This information may be critical to secure resources and ensure support for caregivers and healthcare leaders in implementing antimicrobial stewardship programs and evidence-based SSI preventive practices.
\end{abstract}

Keywords: Antimicrobial resistance, Multidrug resistance, Surgical site infections, Surveillance, Pathogens, Hospital, Saudi Arabia

\footnotetext{
* Correspondence: balkhyh@ngha.med.sa; balkhyh@hotmail.com

${ }^{1}$ Infection Prevention and Control Department, King Abdulaziz Medical City (KAMC), Ministry of National Guard Health Affairs (MNGHA), P.O. Box 22490, 11426 Riaydh, Kingdom of Saudi Arabia

${ }^{2}$ King Saud bin Abdulaziz University for Health Sciences, Riyadh, Saudi Arabia

Full list of author information is available at the end of the article
}

(c) The Author(s). 2020 Open Access This article is licensed under a Creative Commons Attribution 4.0 International License, which permits use, sharing, adaptation, distribution and reproduction in any medium or format, as long as you give appropriate credit to the original author(s) and the source, provide a link to the Creative Commons licence, and indicate if changes were made. The images or other third party material in this article are included in the article's Creative Commons licence, unless indicated otherwise in a credit line to the material. If material is not included in the article's Creative Commons licence and your intended use is not permitted by statutory regulation or exceeds the permitted use, you will need to obtain permission directly from the copyright holder. To view a copy of this licence, visit http://creativecommons.org/licenses/by/4.0/ The Creative Commons Public Domain Dedication waiver (http://creativecommons.org/publicdomain/zero/1.0/) applies to the data made available in this article, unless otherwise stated in a credit line to the data. 


\section{Background}

Surgical site infection (SSI) is a global healthcare problem increasing patient morbidity, mortality, and healthcare cost $[1,2]$. Despite the fact that more than $50 \%$ are preventable [3], SSI remains the most frequent healthcareassociated infections (HAIs) in low and middle income countries, affecting up to $30 \%$ of the patients undergoing surgery $[1,4]$. Even in high income countries, it is still the second frequent type of HAI, accounting for more than $20 \%$ of all HAIs [5]. Several surgical-related practices have been linked to the development of antimicrobial resistance [6]. The presence of resistant pathogens has been shown to augment the clinical and economic impacts of SSI [7]. Therefore, recent SSI guidelines stressed on the appropriate use of antimicrobial prophylaxis to reduce the risk of antimicrobial resistance [6].

Gram positive pathogens (GPPs) are traditionally the most frequently isolated SSI pathogens, with a considerable number of these pathogens are now resistant $[5,8$, 9]. For example, $44 \%$ of Staphylococcus aureus and $20 \%$ of Enterococcus spp. isolated from surgical wounds in the USA are resistant $[8,9]$. Unlike the prevalence of SSI in Saudi Arabia, very few studies focused on the causative pathogens and/or their resistance patterns [10-12]. Moreover, data on surgery-specific pathogens in these reports were absolutely lacking or retrieved from a small number of patients [10-12]. Likewise, very limited data on the resistance patterns of pathogens causing SSI were reported in the Gulf Cooperation Council (GCC) [10] and the Middle Eastern countries [13, 14]. For example, a study that combined aggregate SSI data from 30 developing countries (including some regional ones) could not present data on pathogen profile nor bacterial resistance [15]. The objective of the current study was to estimate the prevalence and extent of resistance of SSI pathogens identified during HAI surveillance in four tertiary care hospitals in Saudi Arabia; additionally, to compare such data to the US National Healthcare Safety Network (NHSN) hospitals.

\section{Methods}

\section{Setting}

Data were collected from four Ministry of National Guard Health Affairs (MNGHA) hospitals; King Abdulaziz Medical City-Riyadh (KAMC-R), King Abdulaziz Medical City-Jeddah (KAMC-J), King Abdulaziz Hospital-Alhassa (KAH), Imam Abdulrahman Bin Faisal Hospital-Dammam (IABFH). MNGHA hospitals are governmentally funded tertiary care hospitals that provide free services for more than 1.5 million Saudi National Guard soldiers, employees and their families. The total bed capacity of the four hospitals is approximately 2200 beds with an average occupancy rate of $72 \%$. Approximately 30,000 surgical procedures are conducted in MNGHA hospitals every year.

\section{Design}

SSI surveillance was prospectively conducted on several surgical procedures performed in four MNGHA hospitals between 2007 and 2016. The surveillance was performed by trained infection preventionists using unified SSI data collection methods, similar to those of the NHSN [16]. The surveillance was targeting selected surgical procedures based on annual risk assessments, approved by the hospital infection control committee. Post-discharge surveillance data were obtained from admission and readmission records as well as surgical follow-up, outpatient clinics, and emergency visits.

\section{Event eligibility}

All surgeries performed on adult patients and was part of the targeted surveillance plan during the study period were initially included. Same-day and outpatient surgeries were excluded. Similarly, SSI events diagnosed clinically without laboratory confirmation were then excluded.

\section{Infection and resistance definitions}

The surveillance definitions and data collection methods followed a locally generated GCC surveillance manual [17] that was based on the NHSN definitions [16]. While rare, more than one pathogen was allowed for a single SSI event. Multidrug resistance (MDR) definitions were retrospectively calculated as per the current NHSN definitions [18] and recent NHSN reports [8, 9]. Cephalosporin-resistant Klebsiella spp. was defined as Klebsiella spp. testing non-susceptible (resistant or intermediate) to at least one cephalosporin agent (ceftazidime, cefotaxime, ceftriaxone or cefepime) [18]. Carbapenem-resistant Enterobacteriaceae (CRE) was defined as Klebsiella spp., Escherichia coli, or Enterobacter spp. testing resistant to imipenem [18]. MDR Gram negative pathogens (GNPs) were defined as pathogens testing nonsusceptible (resistant or intermediate) to at least one agent in at least 3 out of 5 antimicrobial classes; aminoglycosides (amikacin or gentamicin), cephalosporins (ceftazidime, cefotaxime, ceftriaxone, or cefepime), fluoroquinolones (ciprofloxacin or levofloxacin), carbapenems (imipenem or meropenem), $\beta$-lactamase inhibitor (piperacillin or piperacillin/tazobactam) [8, 9]. Only in MDR Pseudomonas aeruginosa, 2 cephalosporins (cefepime and ceftazidime) rather than 4 cephalosporins (above) were considered.

\section{Statistical methods}

Categorical variables were presented as frequencies and percentages while continuous variables were presented as means and standard deviations. Age and gender were calculated for non-duplicate patients only. The distribution of SSI pathogens and their resistance patterns were presented by (name and wound class of) surgical procedures and significant differences were evaluated using chi-square test or Fisher exact test (as appropriate). The distribution of SSI 
pathogens and their resistance in MNGHA hospitals were compared to corresponding rates in NHSN hospitals after pooling data from two published NHSN reports [8, 9]. SPSS (Version 25.0. Armonk, NY: IBM Corp) was used for all statistical analyses.

\section{Results}

\section{SSI events and patients}

Out of 602 SSI events detected, 199 (33.1\%) SSI events were excluded due to lack of microbiological data. As shown in Table 1, 492 pathogens causing 403 SSI events were included in the current analysis. Demographics and clinical characteristics of the included SSIs are shown in Table 1. The average age was $49.5 \pm 18.0$ years and approximately $70.0 \%$ of the patients were females. More than a third $(37.0 \%)$ of procedures had non-clean wounds, mainly clean contaminated. The majority $(75.5 \%)$ of the events were superficial incisional SSI, with $19.4 \%$ deep SSI and 5.1\% organ/space SSI. Only $30.5 \%$ of SSI events were diagnosed before discharge. Approximately $6.3 \%$ of the patients with SSI events died during the same hospitalization.

\section{Causative pathogens}

The distribution and rank order of different pathogens by the type of SSI are shown in Table 2. GNPs were the most common (64.2\%), followed by GPPs (34.3\%) and then fungi (1.4\%). The most frequent pathogens were Staphylococcus aureus (22.8\%), Pseudomonas aeruginosa (20.1\%), Klebsiella spp. (12.2\%), Escherichia coli (12.2\%), Enterobacter spp. (7.7\%), and Enterococcus spp. (5.9\%). Staphylococcus aureus and Pseudomonas aeruginosa were equally the most frequent pathogens in herniorrhaphy and knee prosthesis surgeries. Additionally, Staphylococcus aureus was the most frequent pathogen in cesarean section while Pseudomonas aeruginosa was the most frequent pathogen in coronary artery bypass graft surgery. Escherichia coli was the most frequent pathogen in colon, gallbladder, and other surgeries. In procedures with non-clean wounds, GNPs were more frequent (specially Pseudomonas aeruginosa) while GPPs were less frequent (specially Staphylococcus aureus, Supplementary data, Table 2B).

\section{Resistant pathogens}

Antimicrobial resistance in different pathogens by the type of SSI is shown in Table 3. Approximately $27.7 \%$ of GPPs and $16.1 \%$ of GNPs were resistant. In GPPs, $30.3 \%$ of Staphylococcus aureus was methicillin-resistant (MRSA) and $13.0 \%$ of Enterococcus spp. was vancomycin-resistant (VRE). Approximately $25.0 \%$ of the Klebsiella spp. were cephalosporin-resistant and 5.5\% of Enterobacteriaceae were CRE (11.4\% in Klebsiella spp., 2.0\% in Escherichia coli, and $0.0 \%$ in Enterobacter spp.). The highest frequency of MDR in GNPs was seen in Acinetobacter spp. (58.3\%), followed by Klebsiella spp. (20.4\%) and Escherichia coli (16.3\%).

The distributions of overall resistance by clinical characteristics are shown in Fig. 1. Resistant GPPs (including MRSA or VRE) showed some variability by the type surgery done, being highest with colon surgery $(p=0.013)$. However, there was no significant variability in resistant GPPs by the type of admission, wound class, diagnostic types of SSI, time of diagnosis, nor hospital mortality. Resistant GNPs (including cephalosporin-resistant Klebsiella spp., CRE, MDR Acinetobacter spp., MDR Pseudomonas aeruginosa, MDR Klebsiella spp., or MDR Escherichia coli) showed significant variability with all examined characteristics with the exception of the wound class and type of admission. For example, resistant GNPs were significantly higher with colon surgery but lower with cesarean section compared with all other surgeries combined. Additionally, resistant GNPs were significantly associated with higher mortality, pre-discharge diagnosis of SSI, and with increasing the depth of SSI. None of the different types of resistance was different by the procedure wound class (Supplementary data, Table 3B).

\section{Comparisons with NHSN}

The distribution of pathogens and their resistance patterns in MNGHA compared with NHSN hospitals are shown in Fig. 2. Pseudomonas aeruginosa, Klebsiella spp., Enterobacter spp., Serratia spp., and Acinetobacter spp. were significantly more frequent while Enterococcus, Coagulase negative staphylococci, and fungi were significantly less frequent in MNGHA hospitals compared with NHSN hospitals. MRSA was significantly less frequent while cephalosporin-resistant Klebsiella spp., MDR Klebsiella spp., and MDR Escherichia coli were significantly more frequent in MNGHA hospitals compared with NHSN hospitals.

\section{Discussion}

The current study shows the distribution of SSI pathogens and their resistance patterns in 6 adult surgical procedures performed over 10 years in a multi-hospital healthcare system located in a high income Middle Eastern country. A number of points should be highlighted while we are interpreting the current findings; they represent only laboratory-confirmed SSI events, as 33\% of all SSI events were diagnosed clinically without laboratory confirmation. The data were collected in the presence of a local guideline for surgical prophylaxis consistent with international standards [19]. Additionally, surgical bundle of the Institute for Healthcare Improvement (IHI) was implemented throughout the study [20]. Compliance with the guideline and the surgical bundle, however, has varied widely between surgeries and from time to time (data not shown).

While it is challenging to compare the distribution of SSI pathogens between different studies covering different surgical procedures, Staphylococcus aureus was the most 
Table 1 Demographics and clinical characteristics of surgical site infections (SSIs) in 4 MNGHA hospitals in Saudi Arabia (2007-2016)

\begin{tabular}{|c|c|c|c|c|c|c|c|c|}
\hline & $\begin{array}{l}\text { CSEC } \\
(N=141)\end{array}$ & $\begin{array}{l}\text { COLO } \\
(N=22)\end{array}$ & $\begin{array}{l}\text { CBGB } \\
(N=153)\end{array}$ & $\begin{array}{l}\mathrm{CHOL} \\
(\mathrm{N}=19)\end{array}$ & $\begin{array}{l}\text { HER } \\
(N=16)\end{array}$ & $\begin{array}{l}\text { KPRO } \\
(N=19)\end{array}$ & $\begin{array}{l}\text { Others } \\
(N=33)\end{array}$ & $\begin{array}{l}\text { Total } \\
(N=403)\end{array}$ \\
\hline \multicolumn{9}{|l|}{ Eligibility } \\
\hline Procedures surveyed ${ }^{a}$ & 12,002 (53.9\%) & $181(0.8 \%)$ & 2409 (10.8\%) & $2696(12.1 \%)$ & 1613 (7.3\%) & 1312 (5.9\%) & 2035 (9.1\%) & $22,248(100.0 \%)$ \\
\hline SSI events detected ${ }^{a}$ & $232(38.5 \%)$ & $28(4.7 \%)$ & $208(34.6 \%)$ & $29(4.8 \%)$ & $31(5.1 \%)$ & $31(5.1 \%)$ & $43(7.1 \%)$ & $602(100.0 \%)$ \\
\hline SSI proportion & $232(1.9 \%)$ & $28(15.5 \%)$ & $208(8.6 \%)$ & $29(1.1 \%)$ & $31(1.9 \%)$ & $31(2.4 \%)$ & $43(2.1 \%)$ & $602(2.7 \%)$ \\
\hline Included procedures & 141 (60.8\%) & $22(78.6 \%)$ & $153(73.6 \%)$ & $19(65.5 \%)$ & $16(51.6 \%)$ & 19 (61.3\%) & 33 (76.7\%) & $403(66.9 \%)$ \\
\hline Included specimens ${ }^{a}$ & $160(32.5 \%)$ & $29(5.9 \%)$ & $194(39.4 \%)$ & $28(5.7 \%)$ & $21(4.3 \%)$ & $22(4.5 \%)$ & $38(7.7 \%)$ & $492(100.0 \%)$ \\
\hline \multicolumn{9}{|l|}{ Hospital facility ${ }^{a}$} \\
\hline KAMC-Riyadh & $9(5.0 \%)$ & $22(12.3 \%)$ & $131(73.2 \%)$ & $1(0.6 \%)$ & $3(1.7 \%)$ & $1(0.6 \%)$ & $12(6.7 \%)$ & 179 (100.0\%) \\
\hline KAMC-Jeddah & $76(51.4 \%)$ & $0(0.0 \%)$ & $22(14.9 \%)$ & $13(8.8 \%)$ & $10(6.8 \%)$ & $13(8.8 \%)$ & $14(9.5 \%)$ & $148(100.0 \%)$ \\
\hline KAH-Al hasa & $15(75.0 \%)$ & $0(0.0 \%)$ & $0(0.0 \%)$ & $0(0.0 \%)$ & $0(0.0 \%)$ & $0(0.0 \%)$ & $5(25.0 \%)$ & $20(100.0 \%)$ \\
\hline IAFH-Dammam & $41(73.2 \%)$ & $0(0.0 \%)$ & $0(0.0 \%)$ & $5(8.9 \%)$ & $3(5.4 \%)$ & $5(8.9 \%)$ & $2(3.6 \%)$ & $56(100.0 \%)$ \\
\hline Age, mean $\pm S D^{b}$ & $31.2 \pm 6.5$ & $52.1 \pm 18.0$ & $63.9 \pm 8.7$ & $49.2 \pm 15.1$ & $51.0 \pm 16.1$ & $64.7 \pm 11.4$ & $50.9 \pm 19.4$ & $49.5 \pm 18.0$ \\
\hline \multicolumn{9}{|l|}{ Gender $^{b}$} \\
\hline Male & $0(0.0 \%)$ & $12(54.5 \%)$ & $78(52.0 \%)$ & $5(26.3 \%)$ & $4(25.0 \%)$ & $8(42.1 \%)$ & $13(39.4 \%)$ & 120 (30.0\%) \\
\hline Female & 141 (100.0\%) & $10(45.5 \%)$ & $72(48.0 \%)$ & $14(73.7 \%)$ & $12(75.0 \%)$ & 11 (57.9\%) & $20(60.6 \%)$ & 280 (70.0\%) \\
\hline \multicolumn{9}{|l|}{ Admission } \\
\hline $\mathrm{ICU}$ & $3(2.1 \%)$ & $6(27.3 \%)$ & 153 (100.0\%) & $1(5.3 \%)$ & $0(0.0 \%)$ & $0(0.0 \%)$ & $5(15.2 \%)$ & 168 (41.7\%) \\
\hline Wards & 138 (97.9\%) & $16(72.7 \%)$ & $0(0.0 \%)$ & $18(94.7 \%)$ & 16 (100.0\%) & 19 (100.0\%) & $28(84.8 \%)$ & 235 (58.3\%) \\
\hline \multicolumn{9}{|l|}{ Wound class } \\
\hline Clean & 47 (33.3\%) & $0(0.0 \%)$ & 153 (100.0\%) & $0(0.0 \%)$ & $11(68.8 \%)$ & 19 (100.0\%) & $24(72.7 \%)$ & 254 (63.0\%) \\
\hline Non-clean & 94 (66.7\%) & 22 (100.0\%) & $0(0.0 \%)$ & 19 (100.0\%) & $5(31.3 \%)$ & $0(0.0 \%)$ & $9(27.3 \%)$ & 149 (37.0\%) \\
\hline \multicolumn{9}{|l|}{ SSI type } \\
\hline Superficial & 115 (87.8\%) & $6(27.3 \%)$ & 117 (76.5\%) & 9 (81.8\%) & $8(72.7 \%)$ & 9 (56.3\%) & $20(62.5 \%)$ & 284 (75.5\%) \\
\hline Deep & $14(10.7 \%)$ & $11(50.0 \%)$ & 32 (20.9\%) & $0(0.0 \%)$ & $3(27.3 \%)$ & $3(18.8 \%)$ & $10(31.3 \%)$ & $73(19.4 \%)$ \\
\hline Organ/space & $2(1.5 \%)$ & 5 (22.7\%) & $4(2.6 \%)$ & $2(18.2 \%)$ & $0(0.0 \%)$ & $4(25.0 \%)$ & $2(6.3 \%)$ & 19 (5.1\%) \\
\hline \multicolumn{9}{|l|}{ Diagnosis time } \\
\hline Before discharge & 12 (9.7\%) & $13(76.5 \%)$ & $60(40.5 \%)$ & 9 (52.9\%) & $2(12.5 \%)$ & $3(25.0 \%)$ & $12(40.0 \%)$ & 111 (30.5\%) \\
\hline After discharge & $81(65.3 \%)$ & $3(17.6 \%)$ & $69(46.6 \%)$ & $8(47.1 \%)$ & $10(62.5 \%)$ & $4(33.3 \%)$ & $15(50.0 \%)$ & 190 (52.2\%) \\
\hline On readmission & $31(25.0 \%)$ & 1 (5.9\%) & 19 (12.8\%) & $0(0.0 \%)$ & $4(25.0 \%)$ & 5 (41.7\%) & $3(10.0 \%)$ & $63(17.3 \%)$ \\
\hline \multicolumn{9}{|l|}{ Hospital death } \\
\hline No & 101 (100.0\%) & $11(61.1 \%)$ & 116 (90.6\%) & 15 (100.0\%) & 13 (100.0\%) & $14(100.0 \%)$ & $29(96.7 \%)$ & 299 (93.7\%) \\
\hline Yes & $0(0.0 \%)$ & 7 (38.9\%) & 12 (9.4\%) & $0(0.0 \%)$ & $0(0.0 \%)$ & $0(0.0 \%)$ & $1(3.3 \%)$ & $20(6.3 \%)$ \\
\hline
\end{tabular}

Others, procedures with $\leq 10$ specimens including in order abdominal hysterectomy, appendix surgery, craniotomy, gastric surgery, open reduction of fracture, coronary artery bypass graft with only chest incision, hip prosthesis, and breast surgery

Abbreviations: MNGHA Ministry of National Guard Health Affairs, KAMC King Abdulaziz Medical City, KAH King Abdulaziz Hospital, IAFH Imam Abdulrahman AI Faisal Hospital, CSEC Cesarean section, COLO Colon surgery, CBGB Coronary artery bypass graft with both chest and donor site incisions, CHOL Gallbladder surgery, HER Herniorrhaphy, KPRO Knee prosthesis

${ }^{\mathrm{a}}$ Row rather than column percentages were calculated ${ }^{\mathrm{b}}$ Age and gender were calculated for non-duplicate patients

frequent pathogen in the current study as well as studies done in developed $[5,8,9]$ and developing countries $[1$, $21]$. For example, it was approximately $23 \%$ in the current study compared with 20 to $30 \%$ in these studies [1, 5, 8, 9]. However, GNPs were more prevalent in the current study (64\%) than seen in developed countries (36-46\%) [5, 8, 9]. The prevalence of Pseudomonas aeruginosa and less extent Klebsiella spp. were several folds higher while
Escherichia coli was generally similar to those of the US and European hospitals, even after considering surgeryspecific data $[5,8,9]$. The high contribution of GNPs in the current study was consistent with several reports from Saudi Arabia [10-12] and developing countries [1], that showed contribution rates between 55 and $77 \%$. This may be explained by inadequate hand hygiene practices [22] and high environmental burden of GNPs, that are usually 
Table 2 Distribution of pathogens causing surgical site infections (SSIs) in 4 MNGHA hospitals in Saudi Arabia (2007-2016)

\begin{tabular}{|c|c|c|c|c|c|c|c|c|}
\hline & $\begin{array}{l}\text { CSEC } \\
(N=160)\end{array}$ & $\begin{array}{l}\text { COLO } \\
(N=29)\end{array}$ & $\begin{array}{l}\text { CBGB } \\
(N=194)\end{array}$ & $\begin{array}{l}\mathrm{CHOL} \\
(\mathrm{N}=28)\end{array}$ & $\begin{array}{l}\text { HER } \\
(N=21)\end{array}$ & $\begin{array}{l}\mathrm{KPRO} \\
(N=22)\end{array}$ & $\begin{array}{l}\text { Others } \\
(N=38)\end{array}$ & $\begin{array}{l}\text { Total } \\
(N=492)\end{array}$ \\
\hline All gram positive bacteria & 89 (55.6\%) & $6(20.7 \%)$ & $50(25.8 \%)$ & $6(21.4 \%)$ & $8(38.1 \%)$ & $8(36.4 \%)$ & $2(5.3 \%)$ & $169(34.3 \%)$ \\
\hline Staphylococcus aureus & $67(41.9 \%)$ & $1(3.4 \%)$ & $28(14.4 \%)$ & $3(10.7 \%)$ & $5(23.8 \%)$ & $7(31.8 \%)$ & $1(2.6 \%)$ & $112(22.8 \%)$ \\
\hline Enterococcus spp. & $10(6.3 \%)$ & $5(17.2 \%)$ & $8(4.1 \%)$ & $2(7.1 \%)$ & $3(14.3 \%)$ & $(0.0 \%)$ & $1(2.6 \%)$ & $29(5.9 \%)$ \\
\hline Coagulase negative staphylococci & & & $11(5.7 \%)$ & & & $1(4.5 \%)$ & & $12(2.4 \%)$ \\
\hline Other gram positive & $12(7.5 \%)$ & & $3(1.5 \%)$ & $1(3.6 \%)$ & & & & $16(3.3 \%)$ \\
\hline All gram negative bacteria & 71 (44.4\%) & $23(79.3 \%)$ & $142(73.2 \%)$ & $17(60.7 \%)$ & $13(61.9 \%)$ & $14(63.6 \%)$ & 36 (94.7\%) & $316(64.2 \%)$ \\
\hline Acinetobacter spp. & $1(0.6 \%)$ & $1(3.4 \%)$ & $4(2.1 \%)$ & $1(3.6 \%)$ & & $1(4.5 \%)$ & $4(10.5 \%)$ & $12(2.4 \%)$ \\
\hline Pseudomonas aeruginosa & 19 (11.9\%) & $6(20.7 \%)$ & $52(26.8 \%)$ & $2(7.1 \%)$ & $5(23.8 \%)$ & $7(31.8 \%)$ & $8(21.1 \%)$ & 99 (20.1\%) \\
\hline Klebsiella spp. & $15(9.4 \%)$ & $4(13.8 \%)$ & $29(14.9 \%)$ & $4(14.3 \%)$ & $2(9.5 \%)$ & $1(4.5 \%)$ & $5(13.2 \%)$ & $60(12.2 \%)$ \\
\hline Enterobacter spp. & $8(5.0 \%)$ & $2(6.9 \%)$ & $18(9.3 \%)$ & $2(7.1 \%)$ & $1(4.8 \%)$ & 0 & $7(18.4 \%)$ & $38(7.7 \%)$ \\
\hline Escherichia coli & $17(10.6 \%)$ & $8(27.6 \%)$ & $16(8.2 \%)$ & $5(17.9 \%)$ & $2(9.5 \%)$ & $2(9.1 \%)$ & $10(26.3 \%)$ & $60(12.2 \%)$ \\
\hline Serratia spp. & $1(0.6 \%)$ & & $13(6.7 \%)$ & $1(3.6 \%)$ & & & & $15(3.0 \%)$ \\
\hline Proteus spp. & $7(4.4 \%)$ & & $3(1.5 \%)$ & & $3(14.3 \%)$ & & & $13(2.6 \%)$ \\
\hline Other gram negative & $3(1.9 \%)$ & $2(6.9 \%)$ & $7(3.6 \%)$ & $2(7.1 \%)$ & & $3(13.6 \%)$ & $2(5.3 \%)$ & 19 (3.9\%) \\
\hline Fungi & & & $2(1.0 \%)$ & 5 (17.9\%) & & & & $7(1.4 \%)$ \\
\hline
\end{tabular}

Abbreviations: As in Table 1. Other gram positive pathogens included Streptococcus spp., Streptococcus beta-hemolytic, and Streptococcus pneumonia. Other gram negative pathogens included Citrobacter spp., Bacteroides spp., Morganella morganii, Burkholderia cepacia, and Providencia stuartii

Table 3 Antimicrobial resistance in selected pathogens causing surgical site infections (SSIs) in 4 MNGHA hospitals in Saudi Arabia (2007-2016)

\begin{tabular}{|c|c|c|c|c|c|c|c|c|}
\hline & $\begin{array}{l}\text { CSEC } \\
(N=137)\end{array}$ & $\begin{array}{l}\text { COLO } \\
(N=27)\end{array}$ & $\begin{array}{l}\text { CBGB } \\
(N=155)\end{array}$ & $\begin{array}{l}\text { CHOL } \\
(N=19)\end{array}$ & $\begin{array}{l}\text { HER } \\
(N=18)\end{array}$ & $\begin{array}{l}\text { KPRO } \\
(N=18)\end{array}$ & $\begin{array}{l}\text { Others } \\
(N=36)\end{array}$ & $\begin{array}{l}\text { Total } \\
(N=410)\end{array}$ \\
\hline \multicolumn{9}{|l|}{ Tested pathogens } \\
\hline Staphylococcus aureus & $60(89.6 \%)$ & $1(100.0 \%)$ & $26(92.9 \%)$ & $3(100.0 \%)$ & $3(60.0 \%)$ & $5(71.4 \%)$ & $1(100.0 \%)$ & 99 (88.4\%) \\
\hline Enterococcus spp. & $9(90.0 \%)$ & $2(40.0 \%)$ & 7 (87.5\%) & $1(50.0 \%)$ & $3(100.0 \%)$ & & $1(100.0 \%)$ & $23(79.3 \%)$ \\
\hline Klebsiella spp. (cephalosporins) & $15(100.0 \%)$ & $4(100.0 \%)$ & $24(82.8 \%)$ & $3(75.0 \%)$ & $2(100.0 \%)$ & $1(100.0 \%)$ & $3(60.0 \%)$ & $52(86.7 \%)$ \\
\hline Enterobacteriaceae & $35(92.1 \%)$ & $7(63.6 \%)$ & $37(60.7 \%)$ & $8(80.0 \%)$ & $4(80.0 \%)$ & $3(100.0 \%)$ & $16(80.0 \%)$ & $110(74.3 \%)$ \\
\hline Acinetobacter spp. & $1(100.0 \%)$ & $1(100.0 \%)$ & $4(100.0 \%)$ & $1(100.0 \%)$ & & $1(100.0 \%)$ & $4(100.0 \%)$ & $12(100.0 \%)$ \\
\hline Pseudomonas aeruginosa & $18(94.7 \%)$ & $6(100.0 \%)$ & $51(98.1 \%)$ & $2(100.0 \%)$ & $5(100.0 \%)$ & $6(85.7 \%)$ & $8(100.0 \%)$ & $96(97.0 \%)$ \\
\hline Klebsiella spp. (at least 3 classes) & $10(66.7 \%)$ & $4(100.0 \%)$ & $24(82.8 \%)$ & $4(100.0 \%)$ & $2(100.0 \%)$ & $1(100.0 \%)$ & $4(80.0 \%)$ & 49 (81.7\%) \\
\hline Escherichia coli & $12(70.6 \%)$ & 7 (87.5\%) & $15(93.8 \%)$ & $5(100.0 \%)$ & $1(50.0 \%)$ & $1(50.0 \%)$ & $8(80.0 \%)$ & 49 (81.7\%) \\
\hline \multicolumn{9}{|l|}{ Resistance types } \\
\hline MRSA & $20(33.3 \%)$ & $1(100.0 \%)$ & $6(23.1 \%)$ & $1(33.3 \%)$ & $0(0.0 \%)$ & $2(40.0 \%)$ & $0(0.0 \%)$ & $30(30.3 \%)$ \\
\hline VRE & $0(0.0 \%)$ & 1 (50.0\%) & $1(14.3 \%)$ & $1(100.0 \%)$ & $0(0.0 \%)$ & & $0(0.0 \%)$ & $3(13.0 \%)$ \\
\hline CephR Klebsiella & $1(6.7 \%)$ & $1(25.0 \%)$ & $4(16.7 \%)$ & $2(66.7 \%)$ & $2(100.0 \%)$ & $1(100.0 \%)$ & $2(66.7 \%)$ & $13(25.0 \%)$ \\
\hline CRE & $1(2.9 \%)$ & $2(28.6 \%)$ & $0(0.0 \%)$ & $0(0.0 \%)$ & $0(0.0 \%)$ & 1 (33.3\%) & $2(12.5 \%)$ & $6(5.5 \%)$ \\
\hline MDR Acinetobacter & $0(0.0 \%)$ & $1(100.0 \%)$ & $2(50.0 \%)$ & $1(100.0 \%)$ & & $1(100.0 \%)$ & $2(50.0 \%)$ & 7 (58.3\%) \\
\hline MDR Pseudomonas & $0(0.0 \%)$ & 1 (16.7\%) & $4(7.8 \%)$ & $0(0.0 \%)$ & $0(0.0 \%)$ & $1(16.7 \%)$ & $1(12.5 \%)$ & $7(7.3 \%)$ \\
\hline MDR Klebsiella & $0(0.0 \%)$ & $1(25.0 \%)$ & $3(12.5 \%)$ & $1(25.0 \%)$ & $2(100.0 \%)$ & $1(100.0 \%)$ & $2(50.0 \%)$ & $10(20.4 \%)$ \\
\hline MDR Escherichia coli & $2(16.7 \%)$ & $2(28.6 \%)$ & $0(0.0 \%)$ & $2(40.0 \%)$ & $0(0.0 \%)$ & $0(0.0 \%)$ & $2(25.0 \%)$ & $8(16.3 \%)$ \\
\hline
\end{tabular}

Abbreviations: As in Table 1. Tested pathogens referred to pathogens tested out of pathogens causing SSI; resistance was presented out of pathogens tested; MRSA Methicillin-resistant Staphylococcus aureus, VRE Vancomycin-resistant Enterococcus, CephR Klebsiella Cephalosporin resistant Klebsiella, CRE Carbapenem resistant Enterobacteriaceae, MDR Multidrug resistant gram negative pathogens that tested non-susceptible (resistant or intermediate) to at least one agent in at least 3 out of 5 antimicrobial classes (see Methods) 


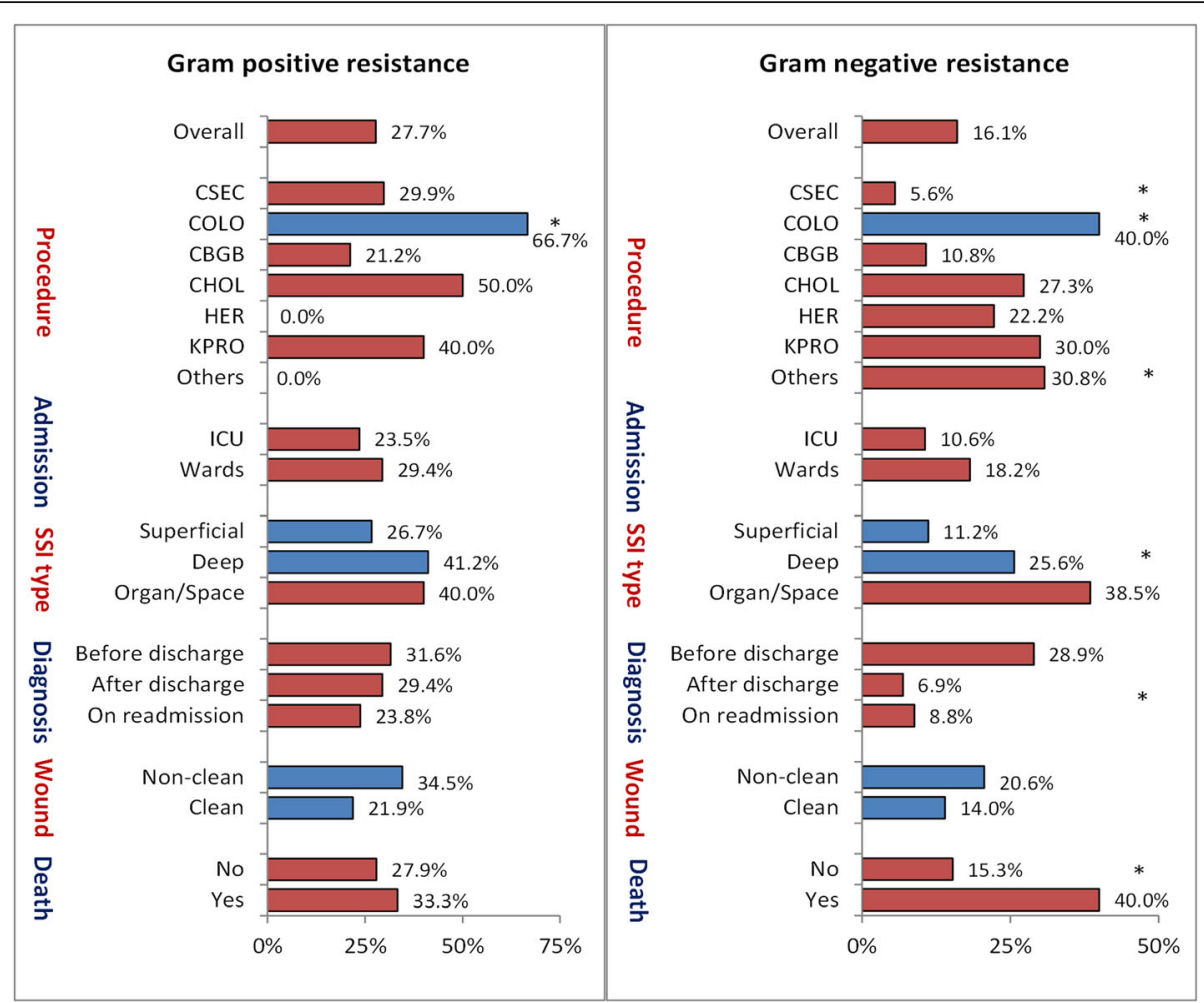

Fig. 1 Overall resistance rates of pathogens causing surgical site infections (SSIs) by clinical characteristics in 4 MNGHA hospitals in Saudi Arabia (2007-2016). Note: Gram positive resistance includes MRSA or VRE. Gram-negative resistance include CephR Klebsiella, CRE, MDR Acinetobacter, MDR Pseudomonas, MDR Klebsiella, or MDR E-coli, as shown in Table 3. * indicate significant differences

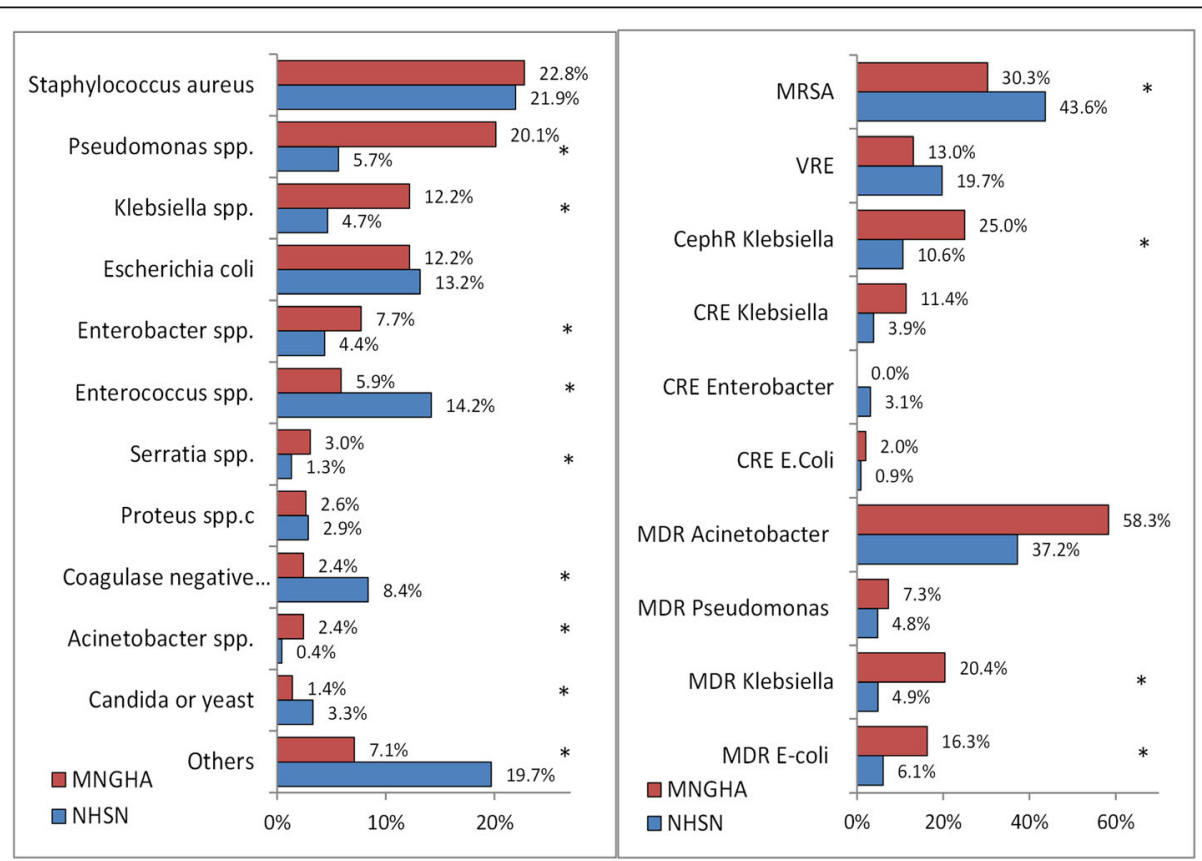

Fig. 2 Comparisons of the percentage of pathogens causing SSI (left) and their resistance of patterns (right*) in MNGHA hospitals (2007-2016) and NHSN hospitals (2009-2014). Abbreviations: As in Table 3; SSI, surgical site infections. NHSN rates were based on the two published NHSN reports (references $[13,14])$. NHSN VRE rate shown was the rate of both Enterococcus faecalis and Enterococcus faecium combined. ${ }^{*}$ indicate significant differences 
more resistant to disinfectants compared with GPPs [23]. However, the high contribution of GNPs may not be simply explained by the difference in the proportions of included procedures as the surgery-specific prevalence of Pseudomonas aeruginosa and Klebsiella spp. in the current study was much higher than corresponding NHSN figures for abdominal, pelvic, cardiac, and orthopedic procedures $[8,9]$. Additionally, it is unlikely to reflect differential antimicrobial selection pressure as the local guidelines for antimicrobial prophylaxis were consistent with international standards [19].

In addition to the low contribution, GPPs causing SSI in the current study were generally less resistant than reported internationally. For example, MRSA rates was 30\% in the current study compared with more than $40 \%$ in USA [8, 9], Europe [5], and Asia [24, 25]. In Saudi Arabia, there has been a great variability in the published MRSA rates, probably due to mixing community and hospital isolates as well as clinical and surveillance isolates [26, 27]. Nevertheless, the current finding was consistent with the local MRSA rates obtained from HAI specimens (mainly wound), which ranged between 16 and 57\% [26]. For VRE, the current rates $(13 \%)$ was comparable to recent reports from Saudi Arabia [28]. Additionally, it was comparable to international rates [5, 24], with exception of North and South American ones which traditionally have very high rates of VRE $[8,9,24]$. Despite the relatively low resistance of GPPs observed in the current and local studies, reports has warned from an increasing trend in the resistance of GPPs in Saudi Arabia, specially VRE, probably due to overuse of broad-spectrum antimicrobials and development of new resistance patterns $[27,28]$.

In addition to higher contribution, GNPs causing SSI in the current study were generally more resistant than reported in US hospitals. For example, all GNPs in the current study (with exception of Enterobacter spp.) were more resistant than NHSN hospitals, with significant difference in cephalosporin-resistant Klebsiella spp., MDR Klebsiella spp., and MDR Escherichia coli $[8,9]$. On the other hand, the current rates were even lower than the extremely high rates of cephalosporin and carbapenem resistance among GNPs reported in some developing countries such as Egypt [13], India [29], and Iran [14]. The high rate of resistance in GNPs in the current study is probably reflecting a wide range of resistance mechanisms in GNPs observed in our hospitals, such as NDM, OXA 48 and MGrb and outer membrabe protein (OMP) resistance [30-34]. The high rate of resistance in GNPs in the current study is quite alarming as it already increased the mortality by $25 \%$. Additionally, this can be used as a justification for initiation and continuation of broad-spectrum antibiotics, leading to a vicious cycle of enhancing resistance. Consistent with current data, a local study showed that $77 \%$ of pathogens isolated from
SSI after abdominal surgery were resistant to the prophylactic antibiotic given preoperatively [11].

With the limited data available locally and regionally, this report can serve as a unique benchmark for caregivers engaged in SSI prophylaxis and antimicrobial stewardship programs. The data were prospectively collected over 10 years by well-trained infection preventionists in 4 hospitals, using the same standard surveillance methodology and the same SSI preventive practices. The relatively large sample size allowed for presenting surgery-specific pathogen distribution and resistance patterns. The use of NHSN resistance definitions allowed for previously unmatched comparisons of resistance patterns between the two differently-matured healthcare systems. Nevertheless, few limitations are acknowledged. The analyzed data were only a sample of a much bigger number of surgeries done in the 4 hospitals during the period covered by the study and almost one-third of SSI were diagnosed clinically. However, these are typical for all studies following the NHSN definitions and NHSN-recommended targeted surveillance methodology. As in other similar studies, underestimation of SSI diagnosis cannot be excluded. However, this should be unlikely, as our population is entitled to free care in our hospitals, which make the likelihood of our patients seeking medical care elsewhere is very low. Despite being beyond of the scope of this paper, the lack of extensive data analysis on the colonization rates and the risk factors that can possibly affect the resistance patterns limit the interpretation of the current findings.

\section{Conclusions}

Staphylococcus aureus remains the most frequent SSI pathogen, with $30 \%$ are MRSA. GNPs are responsible for approximately $64 \%$ of SSI and were generally more resistant than seen in Western countries. Resistant GNPs were associated with increased mortality. Making this information available to caregivers and healthcare leaders is critical to secure resources and ensure support in implementing interventions, such as antimicrobial stewardship programs and evidence-based SSI preventive practices [6].

\section{Supplementary information}

Supplementary information accompanies this paper at https://doi.org/10. 1186/s12879-020-4939-6.

Additional file 1: Table-2B. Distribution of pathogens causing surgical site infections (SSIs) by wound class in 4 MNGHA hospitals in Saudi Arabia (2007-2016). Table-3B. Antimicrobial resistance in selected pathogens causing surgical site infections (SSIs) by wound class in 4 MNGHA hospitals in Saudi Arabia (2007-2016).

\section{Abbreviations}

CBGB: Coronary artery bypass graft with both chest and donor site incisions; CephR : Cephalosporin resistant; CHOL: Gallbladder surgery; COLO: Colon surgery; CRE: Carbapenem-resistant Enterobacteriaceae; CSEC: Cesarean section; GCC: Gulf Cooperation Council; GNPs: Gram negative pathogens; 
GPPs: Gram positive pathogens; HAls: Healthcare-associated infections; HER: Herniorrhaphy; IABFH: Imam Abdulrahman Bin Faisal Hospital; IHI: Institute for Healthcare Improvement; KAH: King Abdulaziz HospitalAlhassa; KAMC-J: King Abdulaziz Medical City-Jeddah; KAMC-R: King Abdulaziz Medical City-Riyadh; KPRO: Knee prosthesis; MDR: Multidrug resistance; MNGHA: Ministry of National Guard Health Affairs; MRSA: Methicillin-resistant staphylococcus aureus; NHSN: US National Healthcare Safety Network; SSI: Surgical site infection; VRE: Vancomycinresistant enterococcus

\section{Acknowledgements}

Infection preventionists of the Infection Prevention and Control Departments of MNGHA.

\section{Authors' contributions}

$A E 1, H B$, and MA1 contributed to study design, data analysis, data interpretation, and writing. SA1, AA, WA, AE2, and SA2 contributed to study design and data collection. ZA, SA3, MA2 contributed to writing and literature search. The authors read and approved the final manuscript.

\section{Funding}

Not applicable.

\section{Availability of data and materials}

The datasets used and/or analyzed during the current study are available from the corresponding author on reasonable request.

\section{Ethics approval and consent to participate}

Institutional Review Boards of King Abdullah International Medical Research Center (Riyadh) waived the ethics approval because no identifying patient information was used during this study. No names, patient numbers, photos, person statements, etc. were used during this study.

\section{Consent for publication}

Not applicable.

\section{Competing interests}

The authors declare that they have no competing interests.

\section{Author details}

${ }^{1}$ Infection Prevention and Control Department, King Abdulaziz Medical City (KAMC), Ministry of National Guard Health Affairs (MNGHA), P.O. Box 22490, 11426 Riaydh, Kingdom of Saudi Arabia. ${ }^{2}$ King Saud bin Abdulaziz University for Health Sciences, Riyadh, Saudi Arabia. ${ }^{3}$ Community Medicine Department, Faculty of Medicine, Mansoura University, Mansoura, Egypt. ${ }^{4}$ King Abdullah International Medical Research Center, Riaydh, Saudi Arabia. ${ }^{5}$ Department of Pathology and Laboratory Medicine, KAMC, Riyadh, Saudi Arabia. ${ }^{6}$ Infection Prevention and Control Department, KAMC, MNGHA, Jeddah, Saudi Arabia. ${ }^{7}$ Infection Prevention and Control Department, Imam Abdulrahman bin Faisal Hospital, MNGHA, Dammam, Saudi Arabia. ${ }^{8}$ Infection Prevention and Control Department, King Abdulaziz Hospital, MNGHA, Al hassa, Saudi Arabia. ${ }^{9}$ Department of Surgery, KAMC, MNGHA, Riyadh, Saudi Arabia. ${ }^{10}$ Department of Surgery, KAMC, MNGHA, Jeddah, Saudi Arabia.

\section{Received: 25 October 2019 Accepted: 28 February 2020} Published online: 07 April 2020

\section{References}

1. Allegranzi B, Bagheri Nejad S, Combescure C, Graafmans W, Attar H, Donaldson L, Pittet D. Burden of endemic health-care-associated infection in developing countries: systematic review and meta-analysis. Lancet. 2011; 377(9761):228-41.

2. Badia JM, Casey AL, Petrosillo N, Hudson PM, Mitchell SA, Crosby C. Impact of surgical site infection on healthcare costs and patient outcomes: a systematic review in six European countries. J Hosp Infect. 2017;96(1):1-15.

3. Umscheid CA, Mitchell MD, Doshi JA, Agarwal R, Williams K, Brennan PJ. Estimating the proportion of healthcare-associated infections that are reasonably preventable and the related mortality and costs. Infect Control Hosp Epidemiol. 2011;32(2):101-14.
4. Bagheri Nejad S, Allegranzi B, Syed SB, Ellis B, Pittet D. Health-careassociated infection in Africa: a systematic review. Bull World Health Organ. 2011;89(10):757-65.

5. European Centre for Disease Prevention and Control (ECDC): Point prevalence survey of healthcareassociated infections and antimicrobial use in European acute care hospitals 2011-2012. 2013. https://ecdc.europa.eu/ sites/portal/files/media/en/publications/Publications/healthcare-associatedinfections-antimicrobial-use-PPS.pdf. Accesed 10 Jan 2018.

6. Allegranzi B, Zayed B, Bischoff P, Kubilay NZ, de Jonge S, de Vries F, Gomes SM, Gans S, Wallert ED, Wu X, et al. New WHO recommendations on intraoperative and postoperative measures for surgical site infection prevention: an evidence-based global perspective. Lancet Infect Dis. 2016; 16(12):e288-303.

7. Campbell RS, Emons MF, Mardekian J, Girgenti D, Gaffney M, Yu H. Adverse clinical outcomes and resource utilization associated with methicillinresistant and methicillin-sensitive Staphylococcus aureus infections after elective surgery. Surg Infect. 2015;16(5):543-52.

8. Sievert DM, Ricks P, Edwards JR, Schneider A, Patel J, Srinivasan A, Kallen A, Limbago B, Fridkin S. Antimicrobial-resistant pathogens associated with healthcare-associated infections: summary of data reported to the National Healthcare Safety Network at the Centers for Disease Control and Prevention, 2009-2010. Infect Control Hosp Epidemiol. 2013;34(1):1-14.

9. Weiner LM, Webb AK, Limbago B, Dudeck MA, Patel J, Kallen AJ, Edwards $J R$, Sievert DM. Antimicrobial-resistant pathogens associated with healthcare-associated infections: summary of data reported to the National Healthcare Safety Network at the Centers for Disease Control and Prevention, 2011-2014. Infect Control Hosp Epidemiol. 2016;37(11):1288301.

10. Khairy GA, Kambal AM, Al-Dohayan AA, Al-Shehri MY, Zubaidi AM, Al-Naami MY, AISaif FA, Al-Obaid OA, Al-Saif AA, El-Farouk OY, et al. Surgical site infection in a teaching hospital: a prospective study. J Taibah Univ Med Sci. 2011;6(2):114-20.

11. Alkaaki A, Al-Radi OO, Khoja A, Alnawawi A, Maghrabi A, Altaf A, Aljiffry M. Surgical site infection following abdominal surgery: a prospective cohort study. Can J Surg. 2019;62(2):111-7.

12. Al-Mulhim FA, Baragbah MA, Sadat-Ali M, Alomran AS, Azam MQ. Prevalence of surgical site infection in orthopedic surgery: a 5-year analysis. Int Surg. 2014;99(3):264-8.

13. El-Kholy AA, Elanany MG, Sherif MM, Gad MA. High prevalence of VIM, KPC, and NDM expression among surgical site infection pathogens in patients having emergency surgery. Surg Infect. 2018;19(6):629-33.

14. Davoudi A, Najafi N, Alian S, Tayebi A, Ahangarkani F, Rouhi S, Heydari A. Resistance pattern of antibiotics in patient underwent open heart surgery with nosocomial infection in north of Iran. Glob J Health Sci. 2015;8(2):288-97.

15. Rosenthal VD, Richtmann $R$, Singh $S$, Apisarnthanarak $A$, Kübler $A$, Viet-Hung N, Ramírez-Wong FM, Portillo-Gallo JH, Toscani J, Gikas A, et al. Surgical site infections, International Nosocomial Infection Control Consortium (INICC) report, data summary of 30 countries, 2005-2010. Infect Control Hosp Epidemiol. 2013;34(6):597-604.

16. Horan TC, Andrus M, Dudeck MA. CDC/NHSN surveillance definition of health care-associated infection and criteria for specific types of infections in the acute care setting. Am J Infect Control. 2008;36(5):309-32.

17. Balkhy H, El-Saed A. Healthcare-associated Infections surveillance manual. 3rd ed. http://ngha.med.sa/English/MedicalCities/AlRiyadh/MedicalServices/ Documents/3rd_edition_Surveillance_Manual.pdf. Accessed 1 Feb 2020; 2018.

18. National Healthcare Safety Network (NHSN). NHSN manual. Patient safety component protocol. Atlanta: Division of Healthcare Quality Promotion, National Center for Infectious Diseases; 2018. https://www.cdc.gov/nhsn/ pdfs/validation/2018/pcsmanual_2018-508.pdf. Accessed 1 Feb 2020.

19. Gulf Cooperation Council - Centre for Infection Control. The GCC Infection Prevention and Control manual. 3rd ed. https://ngha.med.sa/English/ MedicalCities/AlRiyadh/MedicalServices/Lab/Documents/ InfectionControlManual.pdf. Accessed 1 Feb 2020; 2018.

20. Institute for Healthcare Improvement $(\mid \mathrm{HI})$. How-to guide: prevent surgical site infections. Cambridge; 2012. http://www.ihi.org/resources/Pages/Tools/ HowtoGuidePreventSurgicalSitelnfection.aspx. Accessed 1 Feb 2020.

21. Irek EO, Amupitan AA, Obadare TO, Aboderin AO. A systematic review of healthcare-associated infections in Africa: an antimicrobial resistance perspective. Afr J Lab Med. 2018;7(2):796. 
22. El-Saed A, Noushad S, Tannous E, Abdirizak F, Arabi Y, Al Azzam S, Albanyan E, Al Jahdalil H, Al Sudairy R, Balkhy HH. Quantifying the Hawthorne effect using overt and covert observation of hand hygiene at a tertiary care hospital in Saudi Arabia. Am J Infect Control. 2018:46(8):930-5.

23. McDonnell G, Russell AD. Antiseptics and disinfectants: activity, action, and resistance. Clin Microbiol Rev. 1999;12(1):147-79.

24. Zhang Z, Chen M, Yu Y, Pan S, Liu Y. Antimicrobial susceptibility among gram-positive and gram-negative blood-borne pathogens collected between 2012-2016 as part of the Tigecycline evaluation and surveillance trial. Antimicrob Resist Infect Control. 2018;7:152.

25. Chiang CH, Pan SC, Yang TS, Matsuda K, Kim HB, Choi YH, Hori S, Wang JT, Sheng WH, Chen YC, et al. Healthcare-associated infections in intensive care units in Taiwan, South Korea, and Japan: recent trends based on national surveillance reports. Antimicrob Resist Infect Control. 2018;7:129.

26. Nazeer A, Al-Tawfiq JA. Methicillin-resistant Staphylococcus aureus metrics for patients in Saudi Arabia. J Infect Dev Ctries. 2012;6(3):223-33.

27. Yezli S, Shibl AM, Livermore DM, Memish ZA. Antimicrobial resistance among gram-positive pathogens in Saudi Arabia. J Chemother. 2012;24(3): 125-36.

28. Abdallah M, Al-Saafin M. Overview of prevalence, characteristics, risk factors, resistance, and virulence of vancomycin-resistant Enterococci in Saudi Arabia. Microb Drug Resist. 2019;25(3):350-358

29. Bhardwaj N, Khurana S, Kumari M, Malhotra R, Mathur P. Pattern of antimicrobial resistance of gram-negative bacilli in surgical site infections in in-patients and out-patients at an apex trauma center: 2013-2016. J Lab Physicians. 2018;10(4):432-6.

30. Zaman TU, Alrodayyan M, Albladi M, Aldrees M, Siddique MI, Aljohani S, Balkhy $\mathrm{HH}$. Clonal diversity and genetic profiling of antibiotic resistance among multidrug/carbapenem-resistant Klebsiella pneumoniae isolates from a tertiary care hospital in Saudi Arabia. BMC Infect Dis. 2018;18(1):205.

31. Balkhy HH, El-Saed A, Al Johani SM, Francis C, Al-Qahtani AA, Al-Ahdal MN, Altayeb HT, Arabi Y, Alothman A, Sallah M. The epidemiology of the first described carbapenem-resistant Klebsiella pneumoniae outbreak in a tertiary care hospital in Saudi Arabia: how far do we go? Eur J Clin Microbiol Infect Dis. 2012:31(8):1901-9.

32. Uz Zaman T, Albladi M, Siddique MI, Aljohani SM, Balkhy HH. Insertion element mediated mgrB disruption and presence of ISKpn28 in colistinresistant Klebsiella pneumoniae isolates from Saudi Arabia. Infect Drug Resist. 2018;11:1183-7.

33. Zowawi HM, Sartor AL, Sidjabat HE, Balkhy HH, Walsh TR, Al Johani SM, AlJindan RY, Alfaresi M, Ibrahim E, Al-Jardani A, et al. Molecular epidemiology of carbapenem-resistant Acinetobacter baumannii isolates in the Gulf Cooperation Council States: dominance of OXA-23-type producers. J Clin Microbiol. 2015:53(3):896-903.

34. Alghoribi MF, Gibreel TM, Farnham G, Al Johani SM, Balkhy HH, Upton M. Antibiotic-resistant ST38, ST131 and ST405 strains are the leading uropathogenic Escherichia coli clones in Riyadh, Saudi Arabia. J Antimicrob Chemother. 2015;70(10):2757-62.

\section{Publisher's Note}

Springer Nature remains neutral with regard to jurisdictional claims in published maps and institutional affiliations.

Ready to submit your research? Choose BMC and benefit from:

- fast, convenient online submission

- thorough peer review by experienced researchers in your field

- rapid publication on acceptance

- support for research data, including large and complex data types

- gold Open Access which fosters wider collaboration and increased citations

- maximum visibility for your research: over $100 \mathrm{M}$ website views per year

At $\mathrm{BMC}$, research is always in progress.

Learn more biomedcentral.com/submissions 